\title{
Research on the Incentive Mechanism of Hidilao Hotpot's Employees Based on Grounded Theory
}

\author{
Chen Chen \\ School of Management, Jinan University, Guangzhou, China \\ Email: jnuchenchen@163.com
}

How to cite this paper: Chen, C. (2018) Research on the Incentive Mechanism of Hidilao Hotpot's Employees Based on Grounded Theory. Journal of Human Resource and Sustainability Studies, 6, 118-130. https://doi.org/10.4236/jhrss.2018.61031

Received: March 5, 2018

Accepted: March 26, 2018

Published: March 29, 2018

Copyright $\odot 2018$ by author and Scientific Research Publishing Inc. This work is licensed under the Creative Commons Attribution International License (CC BY 4.0).

http://creativecommons.org/licenses/by/4.0/

\section{(c) (i) Open Access}

\begin{abstract}
The traditional classical incentive model only reveals the general rule of organizational incentive, and does not give specific operation rules. The matching between organizational incentives and employee needs is still black box, and it does not reveal its core operation mechanism from the perspective of mechanism. This paper took through the literature review, the Hidilao Hotpot company as a case study, through a variety of ways to collect data, the use of grounded theory to encode data analysis, and ultimately extracted 58 concepts, 26 sub-areas, 7 main areas, concluded that the Hidilao Hotpot Employee motivation formed the path, and ultimately extracted the micro-level employee motivation mechanism model. The research result of this article comes from the practice of the enterprise, which has enlightenment to the organizational incentive of the traditional catering industry and also provides a micro-research perspective and systematic mechanism research for the incentive field.
\end{abstract}

\section{Keywords}

Incentive Mechanism, Grounded Theory, Hidilao Hotpot

\section{Introduction}

Since 2011, Professor Huang Tieying's "The Sea, Since You Learn" published, a reputation of Hidilao Hotpot is further covered with a mysterious aura, but the Zhang Yong administration also pushed to one that cannot imitate, prohibitively high, such a halo of catering enterprises is to the body fierce competition, serious homogenization of the catering industry in the breakout success, thought-provoking [1]. And the book "Seabed Fishing, You Can't Learn" is a landmark book that 
pushed the undersea bottom to the altar of management. But this book focuses on the description of the brilliance of human nature and the feelings of the employees. The analysis of the methods is almost zero, and the illusion of "learning will not" is unavoidable.

Currently involved in human development, enterprise culture, marketing strategy, dual ability, organizational commitment, organizational motivation, customer loyalty and other academic research on Hidilao Hotpot case of academia, from organization management perspective to different management perspectives on the analysis of Hidilao Hotpot, Hidilao Hotpot on the successful password puzzle provides a rich debris, but not yet in-depth study from the perspective of employee for the formation process of employee motivation system, employees in the Hidilao Hotpot service are undoubtedly a fortune, and a

large number of previous academic achievements will provide a rich source of information and a solid theoretical support for this paper.

Dave Ulrich, the pioneer of human resource management, believes that those traditional competitive factors, such as cost, technology, distribution, manufacturing and product characteristics, can be duplicated sooner or later [2]. Only human is the most flexible variable in organization and the most uncontrollable factor. Therefore, in the management of the organization, the study of "human" is essential. This paper will trace the origin of the principle of the Hidilao Hotpot company as a case, from the perspective of individual employees, seeking common at the micro level, the formation mechanism of the grounded theory, research of employee motivation, so as to form a dynamic mechanism for organization to provide a reference system, high quality and efficient operation at the same time to decrypt the success of Hidilao Hotpot, the engine which provides suggestions and measures to optimize reflection that has the reference value for the management practice of the catering enterprises even more industries.

\section{Literature Review}

\subsection{The Study of Classical Theory Related to Incentive}

The root causes of incentives can be divided into internal causes and external causes [3]. In general, the motivation theories of foreign scholars mainly include four categories: content, process, correction and synthesis. The content based incentive theory is represented by Maslow's hierarchy of needs, ERG theory, and two factor theory. The process incentive theory shows that only by finding the close influence factors between employees' needs and behaviors and building necessary connections can employees expect the behaviors of enterprises to expect. The main representative is the modified incentive theory reinforcement theory, through positive reinforcement or negative reinforcement, two kinds of ways to maintain employee behavior continue or disappear, so as to guide the correct direction of employee behavior [4]. Comprehensive incentive theory in learning, research and practice, a comprehensive analysis of the above three theories, to avoid the single section, the merit, the whole process reflects more 
intuitive motivation, Potter-Lawler model is typical of this kind of form.

Incentive is a psychological category, and incentive mechanism refers to the way in which the incentive agent interacts with the incentive objects in the organizational system. The essence of the incentive mechanism is to stimulate the motivation of the members of the organization, to make their goals consistent, and to move forward towards the expected common goal. Zhang Weiying should take into account the incentive compatibility factors, while also considering the goals and incentive constraints of the incentive mechanism design, without violating the seven basic principles of the incentive mechanism.

Comprehensive classic incentive theory and the current theory is extended, most station at the organizational level study of different incentives, such as salary, employment relationship, system design and other debris, meet the staff of different types and levels of demand, so that employees make certain workers so as to achieve the organization's objective behavior, but not all the incentive behavior will achieve organizational expectations, then how to concretely and accurately meet the fundamental needs of employees, to motivate the employees, is still a black box, which requires the staff as the main research subject, exploring the formation mechanism of staff motivation, on the basis of the specific process of staff motivation so as to achieve the formation of an antidote against the disease.

\subsection{The Meaning of Power Mechanism}

The word "mechanism" derives from the Greek language. It originally refers to the construction and operation principles of machines, and refers to the internal working ways of things, including the interrelations between the components concerned and the interconnections of all kinds of changes [5]. The so-called power refers to all factors that cause, promote and motivate the developers to advance and strive for the established goals, including motivation and desire in Psychology [6].

Liu Hengjiang and Chen Jixiang summarized the research results of the domestic and foreign industrial cluster's power mechanism, summed up the concept of the power mechanism, and summed up two aspects of the industrial cluster's driving mechanism: the endogenous power mechanism and the excitation power mechanism. Yang Xinrong [7] and Nan Hongna put forward the enterprise human resources development dynamic mechanism of meaning, namely the operation system of a power enterprise human resource development throughout the whole process of the formation of promoting factors, through a rational system to reflect the various factors promoting the mode of interaction. Sun Bing put forward the concept of independent innovation dynamic mechanism, refers to the mutual relation and mechanism of dynamic factors to promote the enterprise independent innovation activities, as well as the relationship between various dynamic factors and external environment formed by the maintenance and improvement of the mechanism of the total and. Li Shuo [8], through the study 
of the dynamic mechanism of enterprise organizational change, divides the dynamic mechanism into two parts: external power and endogenous power. Hao Yingqi [9] put forward the concept of dynamic mechanism in the management system of multi discipline research based on incentive mechanism and dynamic mechanism, will be defined as: the theory of dynamic mechanism is the power management system will work as the dependent variable, the power and duty, as independent variables, policy system design organization, so as to construct the effective guidance incentive restriction and control mechanism, the organization system should play a function in the mechanism, rather than in people under the control of the operation, the goal is the pursuit of the realm of management in action.

The field of power system is still in the growth stage, in the field of research on enterprise power mechanism is still little, existing research mostly from the framework of dynamic mechanism of organization mechanism or macro expound some aspect ability, its internal micro specific mechanism remains to be further explored in this paper from the micro level to further inquiry.

\subsection{Research on Motivation Mechanism of Employees at the Micro Level}

The American scholar J Cook put forward three factors of employee motivation: need to succeed, the desire to learn, contribute to desire; Ford Motor Co President Lynda Ford in the "management forum" pointed out that incentives should be the need to respect the staff achievements It differs from man to man., labor; Yang Tao and Ma Jun local new generation staff and the existing organizational incentive system is the value demand and job matching, results show that the power driven work of local staff as extrinsic motivation, intrinsic motivation decreased with the increase of age intergenerational organization incentive, supply and demand, the new generation employees work value, can significantly improve the creativity. Hao Yingqi thinks that the microstructure of power mechanism is composed of three parts: power, responsibility and interest. Interest is the initial source of employee motivation, responsibility is the carrier of power, and power is the necessary guarantee for fulfilling responsibility [9].

However, the implementation of incentives so that employees have a positive work motivation is not enough for employees, "mechanism" should be the Constitution and law is relatively stable, so strictly speaking, power generation has not formed a mechanism, in fact most of the research literature is also more than that on the micro level of individual employees the mechanism still exists. The micro level this paper focuses on the dynamic mechanism of the reference of Professor Hao Yingqi model of the micro driving mechanism, the organization of employees based on individual perspective, reveals the interrelationship between the various elements of the power system, to observe the micro dynamic structure in the overall arrangement of the organization, in accordance with the macro structure attached to the driving mechanism with the formation of staff 
motivation [9].

\section{Case Company Brief Introduction}

\subsection{Brief Introduction of Hidilao Hotpot}

Sichuan Haidilao food Limited by Share Ltd was founded in March 20, 1994, is an operating Sichuan Hot pot, with around Hot pot in one of the characteristics of large retail chain enterprises. The company has always been adhering to the "service first, customer first" philosophy, to innovation as the core, to change the traditional standard, single service, personalized special services, is committed to providing pleasure for customers dining services; in the management, advocating hands to change the fate of the values, create a fair working environment the staff, the implementation of humanistic and family oriented management mode, enhance the value of staff.

Over the past twenty years, the company has 190 direct restaurants in mainland China. There are 2 direct restaurants in Taiwan, China, including 4 in Singapore, 1 in Losangeles, 3 in Seoul and 1 in Tokyo, Japan. Seabed has seven large modern logistics and distribution bases and two base production bases. The company now has become the domestic and foreign outstanding brand enterprises, successfully create a high degree of credibility, a Sichuan Hot pot characteristics, combining Sichuan food culture "Shu, Shu wind rich high quality brand Hot pot.

\subsection{Review of Relevant Literature on the Incentive of Hidilao Hotpot's Staff}

Parasuraman et al. put forward four differences between service industry and other industries: service is invisible; service heterogeneity; production and consumption cannot be separated; service cannot be stored. Among them, the third characteristic is mainly described in the service delivery process, compared with other industries, the service industry is more than a customer, and the employees will interact with the workplace. Because customers and employees in the process of service delivery facing each other to interact, the staff in the process of service delivery to the customer will be aware of every act and every move, so the service behavior of employees in service encounter, became one of the most important factors affecting customer perception of service satisfaction, this is where the special service industry and its charm, so for any enterprise staff management is particularly important. Anything on the bottom can be duplicated. Only the people on the bottom of the sea can't copy it. The employees of the bottom fishing industry are the core competitiveness of the fishing industry [1]. Can the management model of the seafloor be replicated? At present, the theory research on Hidilao Hotpot can be divided into five aspects: one is to study from the perspective of business model, two is to study from the perspective of corporate culture, the three is from the research service and service marketing perspective, four is from the perspective of human resource management, five is a compre- 
hensive study of Hidilao Hotpot.

The research content of this paper, the extraction and dynamic mechanism of Hidilao Hotpot theme literature related to the research, from the perspective of incentive has elaborated the relevant literature and Hidilao Hotpot motivation in human resource management, divided into care incentive, decentralized incentive, profit driven motivation and comprehensive evaluation. From the perspective of literature analysis, although the perspective of Bahai fishing is diversified, the depth of research is far from enough, especially for the core capital of seafloor, the study of employees and the formation of employee motivation mechanism. Hidilao Hotpot is a labor intensive service catering enterprises, on the one hand, because of its products is a kind of experience products, simultaneous production and consumption, need to complete the interaction between the employees and the customers, on the other hand, due to the customer for the diversity and complexity of interaction with the hotel and hierarchical service scene the uncertainty determines its service products than service industry production more difficult. Therefore, grass-roots employees as the final agent and the last creator of corporate profits are very important for increasing customer perceived service quality, improving customer satisfaction and the survival and development of enterprises. From the current literature, from the perspective of motivation research on Hidilao Hotpot mostly from the existing management measures, to verify the existing incentive theory, the depth of research, the theoretical results with the existing mainstream view is similar, lack of innovation, analysis on the formation mechanism of staff motivation is not very deep and systematic. The Hidilao Hotpot on employee motivation have failed to touch the fundamental, are not systematically one-sided to incentives of one-sided explanation and verification, in view of the lack of Hidilao Hotpot dynamic mechanism complete, in-depth exploration and discussion, so from the perspective of employee, Hidilao Hotpot company as a case, it is particularly necessary study on Mechanism of employee motivation formation by the method of grounded theory.

\section{Research Design}

\subsection{The Logical Process of Grounded Theory}

Grounded theory focuses on the continuous comparison and induction analysis of data in the process of research. Its purpose is to build theories based on empirical data, while ensuring the integrity and scientificity in the process of theoretical evolution. The theory of taking root emphasizes the construction of new theories and explores the understanding of things or phenomena. The process of data collection and analysis is emphasized in the process of research. After obtaining the data, we analyze and code the data, get the new concepts and categories, and compare the new concepts and categories with the original ones, and then carry out the new data collection and analysis based on this. The relationship between categories is the theory obtained by the research. When the new 
information no longer emerges the concept, the class and the new relationship, that is, the theory is saturated.

This paper adopts the procedures of grounded science analysis method, through open encoding, encoding and encoding three spindle selective encoding by analysis of data, establish different context through the story line will be all is associated with the formation of theory, procedures of grounded theory that the research process can not eliminate people's awareness and understanding of the reality of supervisor.

\subsection{Data Collection}

Case studies are different from other research methods, and do not clearly represent the boundary of data collection. Therefore, we should collect as much information as possible to ensure that most of the research questions can be supported by enough evidence. The data collection of this article mainly adopts two methods of literature research and interview, which are complementary and verified. The collection process of the data is strictly followed by the principle of grounded theory, and the data are collected, analyzed and recorded in a nonlinear way. At the same time of data collection, it will be sorted and analyzed by different personnel. The old and new data will be compared repeatedly, so as to direct the next collection. When data is no longer able to provide new information, the collected data has reached a theoretical saturation state and the collection work is temporarily stopped. The sources of data collection are in-depth interview, field observation, literature research, portal information and internal documents. By integrating and comparing the data of these 5 sources, the degree of consistency within the data is validated to ensure the credibility of the data. It is shown in Table 1.

\subsection{Coding Process}

Through the open coding, the spindle coding and the selective coding three level codings, the analysis of the data of the model is analyzed.

Open code is an open and neutral attitude to break down the original data, and define the process of phenomenon, labeling, conceptualization and categorization. This process extracts 59 valid concepts and 29 subcategories from 38 text labels and 16 interview labels. An example of the open coding section is shown in Table 2.

Further refinement, abstraction and development of the sub categories obtained in the open code make the attributes and dimensions of the category more specific. In this process, the split data in the initial open code is rearranged, the original material is deeply analyzed, and the inner link between the categories is excavated. In the original data in the concept class is analyzed, it is necessary to consider the relationship between these concepts themselves, but also discusses the raw materials corresponding to these concepts to convey the intention and motivation, finally get the benefits, commitment and constraint 
Table 1. Interview.

\begin{tabular}{cccc}
\hline Time & Target & Position & Location \\
\hline 2017/1/9 10:00-11:00 & He Ningyan & Lobby Manager & The lobby at Beijing Road store \\
2017/1/10 10:00-11:00 & Liang Ting & Lobby Manager & The lobby at Tiyu west Road store \\
2017/1/11 14:00-15:00 & Li Ling & Human Resources Department & 703A at Gangyi building \\
2017/6/19 10:00-13:00 & Yu Cong & Store Manager & 503 loge at Beijing Road store \\
2017/6/19 13:00-15:00 & Piao Piao & Waiter & 503 loge at Beijing Road store \\
2017/8/21 11:00-13:00 & Yu Cong & Store Manager & 505 loge at Beijing Road store \\
2017/8/21 13:00-15:00 & Zi Wei & Waiter & The lobby at Beijing Road store \\
2017/8/31 12:00-14:00 & Cai Shen & Waiter & The lobby at Tiyu west Road store \\
2017/10/10 17:00-19:00 & Yu Cong & Store Manager & 505 loge at Beijing Road store \\
\hline
\end{tabular}

Attached: This is derived from the author.

Table 2. Open coding part example.

\begin{tabular}{|c|c|c|c|}
\hline Description & Definition (ax) & $\begin{array}{c}\text { Conceptualization } \\
\text { (aay) }\end{array}$ & Categorization $(\mathrm{Az})$ \\
\hline $\begin{array}{l}\text { As everyone knows, managers and employees in the catering } \\
\text { industry, no matter how the scientific management system and } \\
\text { work flow, and behavior first determine not totally executed, } \\
\text { but must first determine the system and processes is of much } \\
\text { benefit to themselves, and then examine decision makers and } \\
\text { implementation efforts. }\end{array}$ & $\begin{array}{l}\text { How good is the } \\
\text { benefit of the system } \\
\text { and the process to } \\
\text { yourself first, al }\end{array}$ & $\begin{array}{l}\text { aal } \\
\text { System validity } \\
\quad(\mathrm{a} 1, \mathrm{a} 47)\end{array}$ & $\begin{array}{c}\text { A1 system validity } \\
\text { (aa1, aa12, aa35) }\end{array}$ \\
\hline $\begin{array}{l}\text { What is the legacy of this management myth, which is regarded } \\
\text { as a legend by the outside world? The sea of this phenomenon is } \\
\text { the explanation of "mentoring", is the master apprentice, } \\
\text { mature one sent to a patient. }\end{array}$ & $\begin{array}{l}\text { Relying on the system } \\
\text { of apprenticeship to } \\
\text { inherit the classic al1 }\end{array}$ & $\begin{array}{l}\text { aa9 } \\
\text { Apprenticeship } \\
\text { training (a11, a17, a27) }\end{array}$ & $\begin{array}{l}\text { A7 training model } \\
\text { for apprenticeship } \\
\text { Formula (aa9) }\end{array}$ \\
\hline $\begin{array}{l}\text { The corporate governance structure is the arrangement of } \\
\text { Pyramid Hidilao Hotpot type post, the structure and the star of } \\
\text { the Hidilao Hotpot enterprises pay homage to the Qingdao } \\
\text { Haier group is very similar. The two enterprises with the head } \\
\text { of the sea word have strong executive power, and can it be } \\
\text { considered that this kind of corporate governance has played an } \\
\text { important role? }\end{array}$ & $\begin{array}{l}\text { The Pyramid type } \\
\text { management structure } \\
\text { makes the staff } \\
\text { executive strong a13 }\end{array}$ & $\begin{array}{l}\text { aal1 } \\
\text { Company structure } \\
(\mathrm{a} 13, \mathrm{a} 96)\end{array}$ & $\begin{array}{l}\text { A9 management } \\
\text { structure } \\
\text { (aa11, aa58) }\end{array}$ \\
\hline $\begin{array}{l}\text { Encourage employees to use both hands to change their lives, so } \\
\text { that the height, appearance, and academic qualifications are not } \\
\text { dominant employees to become intimate and good in } \\
\text { cooperation with the first class talent. }\end{array}$ & $\begin{array}{l}\text { Motivate employees to } \\
\text { use their hands to } \\
\text { change their fate a18 }\end{array}$ & $\begin{array}{l}\text { aa14 } \\
\text { Change the fate } \\
(\text { a18, a70) }\end{array}$ & $\begin{array}{l}\text { A11 changes the } \\
\text { desire for fate } \\
\text { (aa14, aa29, aa45) }\end{array}$ \\
\hline The staff of seabed are struggling to change their fate. & $\begin{array}{l}\text { Work goals are highly } \\
\text { consistent with } \\
\text { personal goals, a19 }\end{array}$ & $\begin{array}{c}\text { aa15 goal } \\
\text { normalization (a19) }\end{array}$ & $\begin{array}{c}\text { A12 personal goals } \\
\text { and organizational } \\
\text { goals (aa15) }\end{array}$ \\
\hline $\begin{array}{l}\text { A manager of seabed said that bailing had set up a supervision } \\
\text { measure for the employee's giving behavior at a time. An } \\
\text { unusual person would give an investigation to the donated } \\
\text { personnel. There must be corruption without the right to } \\
\text { supervise. }\end{array}$ & $\begin{array}{l}\text { Regulatory measures } \\
\text { for discounts and gifts, } \\
\text { a21 }\end{array}$ & $\begin{array}{c}\text { aa16 } \\
\text { Regulatory measures } \\
(\mathrm{a} 21, \mathrm{a} 56, \mathrm{a} 57, \mathrm{a} 93)\end{array}$ & $\begin{array}{l}\text { A13 } \\
\text { Supervision and } \\
\text { assessment (aa16, } \\
\text { aa50, aa51, aa52) }\end{array}$ \\
\hline
\end{tabular}

Attached: This table is derived from the author. 
mechanism, responsibility, organization, guidance, power to the cultural field of 7 the main category, as shown in Table 3.

The last is the core encoding, is an integrated and refined process, mainly is the development of a core category from the main category, probe into the relationship between the core category and related main category and vice category, then set up a to cover all the concepts and categories of the theoretical framework, and finally to the story line in the form of description of the relationship between the the elements of the theoretical framework and relates to all information phenomena and events. Has seven main categories in this paper were spindle encoding stage, "interest", "guide" and "restraint mechanism" and "promise" and "cultural field" and "empowerment", "responsibility", which "profit driven" is divided into two levels of physical layer and fine God, the general use of "causal conditions-context-conditions-phenomenon intermediary action/interaction strategy results" the canonical model, the categories are linked together through the comparison and study of the theme and the analysis of the existing literature, eight main categories will eventually refine a core category, namely the micro dynamic mechanism model.

\subsection{Model Construction}

After three levels of coding, according to the research on the formation of the power mechanism of the seafloor fishing workers, the internal logic structure of the micro dynamic mechanism model is obtained based on the above description and sorting out the relationship between the various main categories (Figure 1).

In the course of work within the organization in the Hidilao Hotpot, Hidilao Hotpot staff hope to get higher than peers, rich material reward, hope for their family to get the care of compensation, at the same time compared to other

Table 3. Main category and sub category.

\begin{tabular}{|c|c|}
\hline Main category & Sub category \\
\hline & Material: Institutional titer, family care, material stimulation \\
\hline Interest driven & $\begin{array}{l}\text { Mental: full trust, respect, working relationship, internal promotion } \\
\text { mechanism, self realization }\end{array}$ \\
\hline $\begin{array}{l}\text { Promise to be } \\
\text { cashed }\end{array}$ & Benchmarking, commitment \\
\hline $\begin{array}{l}\text { Restraint } \\
\text { mechanisms }\end{array}$ & Latent restraint, personal background, supervision and assessment \\
\hline Responsibility & $\begin{array}{l}\text { Job satisfaction, organization and personal goal overlap, job skills, job } \\
\text { responsibilities, genuine service }\end{array}$ \\
\hline $\begin{array}{l}\text { Organizational } \\
\text { guidance }\end{array}$ & $\begin{array}{l}\text { Resource support, teacher apprenticeship training model, efficient com- } \\
\text { munication, target guidance }\end{array}$ \\
\hline Empowerment & Leadership responsibility and empowerment \\
\hline Cultural field & $\begin{array}{l}\text { Enterprise culture infiltration, social relations, leadership style, manage- } \\
\text { ment structure, working atmosphere }\end{array}$ \\
\hline
\end{tabular}

Attached: This table is derived from the author. 


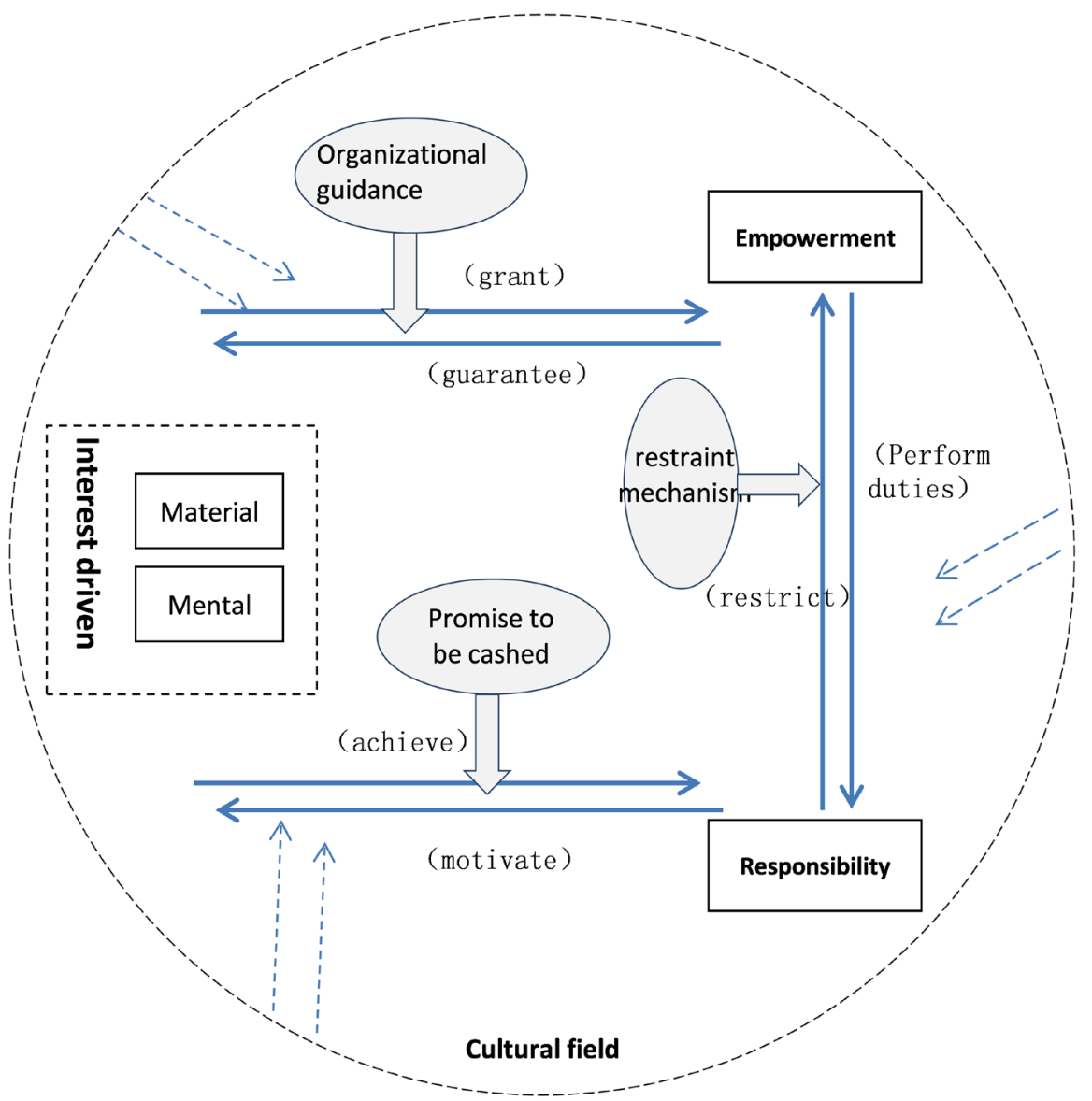

Figure 1. Micro dynamic mechanism model. Attached: This figure is derived from the author.

groups, more eager to receive the equal treatment, respect and trust are eager for success, these benefits will drive the desire of the staff have a certain work motivation to take certain behavioral measures. And Hidilao Hotpot in order to work behavior that the employee's personal goals and organizational goals tend to make the employees have wanted to see, employees get the organization to give the platform, technology, personnel and other resources to support, Haidilao using mentoring mentoring training mode unique. In the interests of the drive guide and a series of organizations under the action of Hidilao Hotpot staff was awarded the full power to better undertake tasks, such as free drinks and snacks domination authority Manicure shoe service, and superior to error tolerance and take behavior and creative employees with a greater degree of flexibility. But human beings are animals with complex emotions. Employees need to be supervised and restrained by the outside world in the process of exercising their powers. Employees will be regularly assessed by their organization in their work. Finally, under the joint action of correct behavior and organizational commitment, employees can get the expected benefits they want, and further stimulate employees' need for further benefits.

It is worth mentioning that, in the closed-loop dynamic mechanism, interac- 
tion between all elements and elements, are subject to different degrees of Oriental culture and China unique social culture, the working people in lower social level with both hands to change the fate of the desire and the desire, respect and trust equality is unusually strong and perfectly logical and reasonable, and the corporate culture, leadership style, management structure, etc. These are fishing in the sea which is reflected and penetration, side of the model case also makes Haidilao employees enough to believe everything you want is here can achieve.

\section{Summing}

\subsection{Research Conclusions}

The enterprise honors the commitment of individual employees through the guidance, constraints, incentives, such as a variety of ways; the enterprise wants to see the work behavior and attitude, but most enterprises have not reached the ideal state; incentives and corporate culture of most enterprises are too superficial form, resulting in enterprises and employees in the state of separation, the two goals away in the same way, so the working enthusiasm of the staff is ineffective. However, the existing incentive theory focuses on the improvement of incentive mechanism. However, the formation of individual motivation is not only influenced by the motivating factors, but also ignored by the analysis of the perfected system and the core mechanism of dynamic formation. However, the theoretical research of the existing power mechanism is relatively scattered. It does not systematically sort out the formation mechanism of employee motivation at the micro level in enterprises, so as to provide guidance for enterprises in practice. The primary and secondary data were collected. Using grounded theory to collect open encoding, encoding, encoding spindle core, the micro level staff motivation mechanism model of seven elements is constructed, thus the following conclusion is drawn:

The microstructure of power mechanism consists of seven parts: power giving, responsibility taking, interest driving, organization and guidance, binding mechanism, promise fulfillment, and cultural field. It is a process of interaction and optimization of all components. The key point of the formation of micro dynamic mechanism is interest driven, which is divided into material level and mental level. It is the essential source of motivation and the ultimate goal of individual pursuit. In the organization guidance and restraint mechanism, commitment to allocate cash three elements of the regulation, promotion of interests, responsibilities, powers of three, the formation of closed-loop dynamic mechanism, each link elements and the dynamic mechanism is embedded in the cultural field, all links are influenced by cultural field.

In this paper, the following research is insufficient, which is also the direction for further research and excavation.

First, the case study is used in this paper, but it is unavoidable that the case study itself is inadequate. Firstly this paper selects the Hidilao Hotpot store, lo- 
cated in Guangzhou, with regional limitations; secondly, this paper selects the enterprise's catering enterprises, with the type of limitation; thirdly, using only one case, although the choice of representative enterprises, the conclusion of the study is not general widely, only local general. Therefore, the future research can enlarge the sample size, and find that the core power mechanism in the process of employee motivation formation can be from different industries and regions by comparing different enterprises across different cases.

Second, this paper adopts the method of grounded theory, the forming process has adopted continuous comparison, memorandum and so many measures to try to overcome the influence of subjective consciousness on the results from the concept to the category, it would influence by researchers and subjective knowledge ability. In the future, we should combine qualitative and quantitative studies as much as possible to improve the value and reliability of the research.

Third, the object of study selects the Hidilao Hotpot staff, although typical, also with particularity, this is a group of foreign workers from the bottom of society, the migrant workers mainly rooted in the course of screening only individual take part in common, adhering to the principle of objectivity, but its power generation is inevitable with a group of the special factors. In the future, we can explore the dynamic mechanism of middle level management or knowledge workers, and enrich the core category of micro dynamic mechanism and the aspect contained in it.

\subsection{Main Innovations}

First, from the micro perspective analyzes the formation mechanism of staff motivation, in the original model occurred on the basis of the key role between the new powers, responsibilities and interests of the three elements of the organization, guidance and restraint mechanisms, promise adjustment promoting factors, improve the two-way closed-loop relationship between the three elements, and put forward the concept of cultural field the domain, permeate all aspects of employee motivation mechanism in [9].

Secondly, using grounded theory research method to research the dynamic mechanism model, from the first original data after encoding, encoding, open spindle core encoding step by step to tease out the seven main categories and a core category, the construction model of micro dynamic mechanism of the field theory of vulnerability, it is more speculative than pure text convincing.

\section{References}

[1] Huang, T.Y. (2011) The Secret of Haidilao. Chinese Entrepreneurs, Z1, 48-67.

[2] Ulrich, D. and Lake, D.G. Organizational Capability: Competing from the Inside out. Bibliography, 319-329.

[3] Robbins, S.P. and Judge, T.A. (2012) Organizational Behavior. Translated by Sun, J.M., Li, Y. and Huang, X.Y., $14^{\text {th }}$ Edition, China Renmin University Press, Beijing, 
450-552.

[4] Zhang, J. (2016) Research on the Incentive Mechanism of the Armed Police Force Financial Cadres Based on Content Motivation Theory. Proceedings of 20165 th International Conference on Social Science, Education and Humanities Research, 11-12 June 2016, Tianjin. https://doi.org/10.2991/ssehr-16.2016.180

[5] Yeung, I.Y. and Tung, R.L. (1996) Achieving Business Success in Confucian Societies: The Importance of Guanxi. Organizational Dynamics, 25, 54-65. https://doi.org/10.1016/S0090-2616(96)90025-X

[6] Gupta, A.K. and Singhal, A. (1993) Managing Human Resources for Innovation and Creativity. Research-Technology Management, 36, 14-18. https://doi.org/10.1080/08956308.1993.11670902

[7] Yang, X.R. (2010) Research on the Dynamic Mechanism of Human Resource Development. China Human Resources Development, No. 5, 92-96.

[8] Li, S. (2014) Research on Organizational Structure Change Theory and Dynamic Mechanism of Enterprise. Oriental Enterprise Culture, No. 16.

[9] Hao, Y.Q. (2007) Research on the Dynamic Mechanism of Management System. Tianjin University, Tianjin. 